\title{
TRAJETÓRIA E ATUAÇÃO POLÍTICA DE GASPAR SILVEIRA MARTINS E JOÃO NUNES DA SILVA TAVARES (JOCA TAVARES): RELAÇÕES DE PODER NA FRONTEIRA PLATINA
}

\author{
TRAJECTORY AND POLITICAL ACT OF GASPAR SILVEIRA \\ MARTINS AND JOÃO NUNES DA SILVA TAVARES (JOCA \\ TAVARES): POWER RELATIONS IN THE PLATINE FRONTIER
}

DOI: http//dx.doi.org/10.15448/21778-3748.2018.2.27083

\author{
Gustavo Figueira Andrade \\ Doutorando em História - UFSM \\ figueirandrade@gmail.com \\ Mônica Rossato \\ Doutoranda em História - UFSM \\ monymarchesan@yahoo.com.br
}

\begin{abstract}
RESUMO: O presente estudo tem por finalidade analisar a trajetória e atuação política de Silveira Martins e Joca Tavares numa região de fronteira (Brasil, Uruguai e Argentina), especialmente no período de instalação da república brasileira no final do século XIX. Ambas as atuações foram marcadas por relações caudilhescas e político-parlamentares e apresentaram o perfil de sua formação enquanto elementos transfronteiriços com forte ligação com o Prata. A partir deste espaço platino que estes personagens, outrora ligados aos partidos Liberal e Conservador, estabeleceram suas redes de relações de poder, manifestadas em seus projetos políticos e práticas sociais. Para tal, nos utilizaremos dos trabalhos de Trindade e Noll (1991), Sérgio da Costa Franco (1988), Helga Picollo (1974; 1992) e Sandra Pesavento (1984), Jonas M. Vargas (2010), entre outros destacam as atuações políticas tanto do parlamentar Gaspar Silveira Martins como do General João Nunes da Silva Tavares (Joca Tavares). Este trabalho se refere às pesquisas desenvolvidas pelos autores junto ao Programa de Pós-Graduação em História da Universidade Federal de Santa Maria, Brasil, que tem por tema as trajetórias e atuações políticas de Gaspar Silveira Martins e de João Nunes da Silva Tavares na região fronteiriça platina e está inserido em um projeto "guarda-chuva" intitulado História da América Platina e os processos de construção e de consolidação dos estados nacionais no século XIX e no início do século XX.
\end{abstract}

PALAVRAS-CHAVES: Caudilhismos; Fronteira; Elites; História Política; Estado Nacional.

ABSTRACT: This paper aims to analyze the political trajectory and performance of Silveira Martins and Joca Tavares in a frontier region (Brazil, Uruguay and Argentina), especially during the period of installation of the Brazilian republic at the end of the 19th century. Both activities were marked by caudillo-political and parliamentary relations and presented the profile of their formation as cross-border elements with strong connection with the La Plata River. From this Platine space these characters, once linked to the Liberal and Conservative parties, established their networks of power relations, manifested in their political projects and social practices. To that end, we will use the works of Trindade and Noll (1991), Sérgio da Costa Franco (1988), Helga Picollo (1974, 1992) and Sandra Pesavento (1984), Jonas M. Vargas (2010), among other who point out the policies of both MP Gaspar Silveira Martins and General João Nunes da Silva Tavares (Joca Tavares). This work refers to the researches developed by the authors with the Postgraduate Program in History of the Federal University of Santa Maria, Brazil, whose theme is the trajectories and political actions of Gaspar Silveira Martins and João Nunes da Silva Tavares in the Platine border region and is inserted in an "umbrella" project titled History 
of Platine America and the processes of construction and consolidation of national states in the XIX and early XX centuries.

KEYWORDS: caudilhismos; frontier; elites; political history; national state

\section{INTRODUÇÃO}

A transição da Monarquia para a República no Brasil, a partir de 1889, substituiu o centralismo monárquico pelas demandas das elites regionais, fortalecendo a criação dos partidos republicanos nos estados membros. No estado do Rio Grande do Sul, a emergência do regime republicano significou uma quebra do Partido Liberal, levando a antiga elite que outrora dominava o cenário político, a buscar uma rearticulação política reunindo liberais, conservadores e dissidentes republicanos em torno do Partido Federalista (1892) (GUTFREEIND, 1979). Este partido, criado em Congresso realizado em Bagé (RS, Brasil) reuniu duas lideranças políticas atuantes tanto no Império quanto no início da República: Gaspar Silveira Martins e João Nunes da Silva Tavares (Joca Tavares), que se contrapuseram ao projeto republicano e a influência comtista e autoritária adotada pela Constituição Estadual do Rio Grande do Sul em 1891. As divergências entre os grupos levaram-nos na articulação da Revolução Federalista (1893-1895), um confronto entre liberais/federalistas e republicanos/positivistas na fronteira sul do Brasil, pela disputa e controle do aparato estatal (SOUZA, 2008).

Tendo em vista este contexto político, este artigo tem por objetivo analisar a trajetória e atuação política de Silveira Martins e Joca Tavares, ambas marcadas por relações caudilhescas e político-parlamentares ${ }^{1}$, numa base fronteiriça platina $^{2}$, manifestadas em seus projetos políticos e práticas sociais. A própria Revolução Federalista (1893-1895) constitui-se como uma possibilidade de análise da complexidade do espaço fronteiriço, a partir da investigação das atuações desses dois personagens.

\footnotetext{
${ }^{1}$ Compreendidas aqui como práticas sociais, atores, discursos, migrações, comportamentos, eleitorais e durante a guerra, vínculos e redes sociais, participação na maçonaria e na vida política platina, herança social e familiar em conflitos platinos, com a apresentação de projetos político para ela desses líderes Gaspar Silveira Martins e João Nunes da Silva Tavares, que tiveram suas trajetórias e atuações nessa região fronteiriça platina.

${ }^{2}$ Neste trabalho, utilizamos os conceitos de região fronteiriça platina, espaço fronteiriço platino, fronteira platina ou região de fronteira como sinônimos. A região fronteiriça platina é entendida aqui como uma região maior que a zona de fronteira (região territorial próxima ao limite político entre os Estados Nacionais Uruguaio e Brasileiro), que abrange o sul do Brasil (Rio Grande do Sul), Uruguai e as Províncias do Litoral da Argentina. O conceito de região fronteiriça platina é pensado aqui, quando nos referimos às relações sociais e circulação de Gaspar Silveira Martins, Joca Tavares e suas famílias, especialmente quando se analisa a Revolução Federalista (1893-1895).
} 
Este texto insere-se no projeto de pesquisa "História da América Platina e os processos de construção e consolidação dos Estados Nacionais do século XIX e início do século XX”, do Programa de Pós-Graduação em História da Universidade Federal de Santa Maria, que tem desenvolvido estudos relacionados a temáticas vinculadas ao espaço platino. Este espaço pode ser caracterizado como uma região fronteiriça, a qual, dependendo do olhar (dos/das historiadores/as) poderá ser percebida com definições e percepções diferenciadas, demonstrando que essa fronteira também pode definir o perfil político de uma sociedade e de uma elite que ali vive.

Sendo assim, realizamos uma reflexão acerca desses dois personagens, como caudilhos e representantes de um espaço fronteiriço platino, que levaram adiante projetos de organização estatal e atuaram na mobilização de recursos materiais e humanos desse espaço para a implementação de seus projetos e interesses, permitindo que também seja analisada a fronteira sobre a perspectiva dessas relações de poder.

GASPAR SILVEIRA MARTINS E JOAO NUNES DA SILVA TAVARES: ELITES, RELAÇÕES DE PODER E ESPAÇO FRONTEIRIÇO PLATINO

O espaço fronteiriço platino configurou-se em um espaço com características próprias na qual seus limites e fronteiras estavam sujeitas ao tempo e a territorialização das elites regionais e dos grupos sociais dominantes (ARRIOLA, 2008). Membros de uma elite do espaço fronteiriço platino, a atuação e territorialização das redes de poder de Silveira Martins e Joca Tavares foram construídas através das origens familiares, da atuação caudilhesca e políticoparlamentar nessa região, que abrange o sul do Brasil (Rio Grande do Sul), Uruguai e as Províncias do Litoral da Argentina. Além disso, as trajetórias políticas destes personagens estiveram entrecruzadas pelas incertezas do período republicano em construção, por apresentarem seus horizontes de expectativas (projetos, desejos) (KOSELLECK, 2006) sobre a organização do Estado brasileiro, conformados por interesses econômicos e políticos de uma elite atuante e inserida no Estado imperial brasileiro e territorializados na região fronteiriça platina.

Um horizonte de expectativas que pode estar presente em um conceito/ideia/projeto político defendido por Gaspar Silveira Martins e Joca Tavares, compartilhado por outros sujeitos, e que forneceu base a um sistema de adesões e alianças em torno dessas ideias. O que, 
por exemplo, alguns autores identificaram como "aliança gasparista" ${ }^{3}$, edificada durante o Império em torno do líder do Partido Liberal na Província do Rio Grande do Sul, Gaspar Silveira Martins, e no desenvolvimento da Revolução Federalista, como um conflito que trouxe a disputa entre diferentes projetos de organização estatal e que gerou um sistema de relações de poder entre diferentes grupos sociais, pela mediação e atuação de Gaspar Silveira Martins e Joca Tavares.

Silveira Martins e Joca Tavares apresentaram-se como homens típicos de fronteira, mobilizando-a como mediadores e caudilhos ${ }^{4}$, atuando entre essa região e outro centro de poder, na conquista de cargos, benefícios, alianças políticas, votos, recursos para a guerra, entre outros. Vejamos isso em suas trajetórias, especialmente durante a Revolução Federalista (1893-1895), em que procuraremos correlacionar suas trajetórias ao contexto republicano do período. Assim, passaremos, em um primeiro momento, a apresentar quem são esses dois personagens.

Gaspar Silveira Martins foi batizado em 5 de agosto de 1835 no departamento de Cerro Largo, vila de Melo, no Uruguai e seus pais, Maria Joaquina das Dores Martins e Carlos Silveira eram naturais da Província do Rio Grande do Sul e possuíam propriedades tanto em território brasileiro como uruguaio. Isso colabora para seu vínculo "binacional" fronteiriço, ou seja, uruguaio e brasileiro. A região onde nasceu e se formou Gaspar Silveira Martins, localizava-se nas terras fronteiriças do Brasil (cidade de Bagé) e Uruguai (vila de Melo).

Silveira Martins tinha cidadania uruguaia e brasileira, fundamentadas pela Constituição Uruguaia e pela Carta Constitucional de 1824. Nesse processo em que Silveira Martins ascendeu o espaço de sua família e da região fronteiriça platina em direção ao centro do poder do Império, o investimento nos estudos de pelo menos um dos filhos, principalmente na formação de bacharel em Direito em Academias Jurídicas, fez parte da estratégia familiar de elites da Província do Rio Grande do Sul, para assim colocar seus membros em contato com a Corte e com o "mundo" da política e com isso, adquirir recursos para sua família e comunidade (VARGAS, 2010) .

\footnotetext{
${ }^{3}$ Pesavento (1984) e Helga Piccolo (1992) identificaram a organização de uma "aliança gasparista", que teve Silveira Martins como mediador entre os grupos dominantes da província e o governo central, obtendo deste favores, privilégios e obras. Essa "aliança gasparista" e o projeto liberal no Rio Grande do Sul foram desmantelados em 1889, com a Proclamação da República e o fim do Império (GUTFREIND, 1979).

${ }^{4}$ Os termos "mediador" e "caudilho" são utilizados aqui como indivíduos que exerciam uma liderança, controle e manipulação de recursos em seu proveito ou de seu grupo, atuando muitas vezes como representantes do Estado em suas localidades, o que dependia da estrutura e volume de sua rede social e da propensão de usar tal rede em seu proveito próprio (Boissevan, 1995).

${ }^{5}$ A relação entre uma dupla cidadania e a sua carreira política pode ser analisada através de sua atuação política, em cargos ocupados, em que se manifestavam ideias e projetos que visavam a criação de uma tarifa especial ao

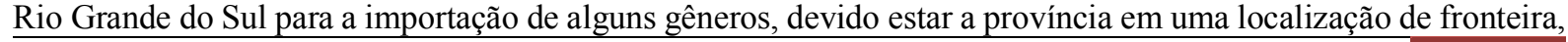


Seus estudos iniciaram em Pelotas, local onde sua família e avô materno tinham propriedades (Rio Grande do Sul/Brasil), mudou-se ao Rio de Janeiro para realizar os estudos preparatórios para ingressar nas Academias do Império, iniciou o curso de Direito na Faculdade de Direito de Olinda e logo em seguida transferiu-o para a Faculdade de Direito de São Paulo, onde se formou no ano de 1856. Exerceu a advocacia no Rio de Janeiro onde atuou como Juiz Municipal. Na Província do Rio Grande do Sul atuou na criação do Partido Liberal Histórico, sendo eleito Deputado Provincial para a Assembleia Provincial do Rio Grande do Sul, em 1862. Em 1872 assumiu como Deputado Geral até 1879. Foi Ministro da Fazenda do Império (1878), e entre 1880 a 1888 atuou como Senador. Em 1889 foi empossado na Presidência da Província do Rio Grande do Sul.

Com o fim do Império em 1889, Silveira Martins foi desterrado do território nacional por um decreto do governo republicano. Em decorrência da ameaça que ele e seus correligionários da fronteira representavam ao governo republicano e, também, pelo fato de ser um liberal, defensor do Parlamentarismo, Silveira Martins foi enviado com sua família a Europa. Esse período em que esteve desterrado representou um momento de construção, reforço e rearticulação das suas redes de poder, quando participou da vida política e intelectual europeia, em contato com reconhecidos lideres, políticos e jornalistas europeus e brasileiros.

Após este período de vivência na Europa, Silveira Martins retornou ao Brasil em fins de 1891. Em 1892, integrou-se ao Partido Federalista (PF), atuando na mobilização e articulação de forças para a Revolução Federalista, na defesa de um projeto político alternativo ao que se tinha implementado. Ou seja, combatia a influência do positivismo na Constituição do estado do Rio Grande do Sul e o federalismo republicano baseado no autoritarismo e centralismo do poder executivo estadual, autonomia dos estados membros em relação a União e enfraquecimento do legislativo estadual. Sua defesa pelo fortalecimento do regime parlamentar, propondo outra forma de organização dos poderes entre estados-membros e a União, traz a tona um projeto federalista que se diferenciava daquele que havia sido implantado, demonstrando as disputas políticas entre as elites regionais (PADOIN, 2005).

\footnotetext{
a construção das estradas de ferro na Província, o projeto de colonização para o Rio Grande do Sul, entre outros. No Senado, ao pronuncia-se contra o projeto de acabar com as associações acatólicas por todo o império, Gaspar Silveira Martins comentou que "nas republicas do Prata há a liberdade civil, onde existem leis que estimulam a vinda de colonos, ao contrário do Brasil, que tem liberdade política mas não tem liberdade civil" (MARTINS, Gaspar Silveira. Anais do Senado Federal. Sessão de 06 jan. 1882) e defendeu o serviço militar obrigatório à Província do Rio Grande do Sul, antecedendo ao período em que os interesses uruguaios teriam de ser protegidos frente às pretensões de Rosas (MARTINS, Gaspar Silveira. Anais do Senado Federal. Sessão de 12 jul. 1882 , p. $\underline{220)}$.
} 
João Nunes da Silva Tavares (1818-1906), conhecido como Joca Tavares ${ }^{6}$, foi um importante chefe político do Partido Conservador durante o período imperial, na cidade de Bagé. Sua família possuía diversas propriedades rurais, inclusive na República Oriental do Uruguai. No que diz respeito à sua trajetória militar, lutou ao lado de seu pai, João da Silva Tavares, pelas forças imperiais durante a Revolução Farroupilha (1835-1845). Além disso, participou da Campanha contra Oribe e Rosas (1851-1852). No entanto, seu prestígio e reconhecimento devem-se, em parte, por ter sido o comandante do piquete que capturou e matou Francisco Solano López em Aquidabã, na fase final da Guerra do Paraguai, conhecida como Campanha das Cordilheiras (PORTO ALEGRE, 1917: 82), vindo a receber em outubro de 1870 do Imperador Dom Pedro II diversas honrarias, dentre elas o título de Barão de Itaqui, de Oficial da Ordem Imperial do Cruzeiro, sendo nomeado Brigadeiro Honorário do Exército Brasileiro.

Foi por diversas vezes Comandante Superior da Guarda Nacional em Bagé (CARVALHO, 2011, p. 123), como também Comandante Militar da Fronteira, que abrangia as cidades de Bagé a Santana do Livramento, entre 1885 e 18867 ${ }^{7}$ Logo após a Proclamação da República, em 1889, por determinação do próprio Presidente da República, Marechal Deodoro da Fonseca, foi nomeado novamente ${ }^{8}$ Comandante Militar da Fronteira, de 1890 a 1891 (REIS, 1911, p. 99; 103). No âmbito político provincial, seguindo os passos políticos de seu pai, Joca foi membro do Partido Conservador por longo tempo, e veio a ser nomeado por D. Pedro II o terceiro Vice-Presidente da Província do Rio Grande do Sul, em agosto de 18859 . Com a Proclamação da República, foi um dos fundadores do Partido Federalista, em 1892, juntamente com Gaspar Silveira Martins e outras lideranças oposicionistas à Júlio de Castilhos. Foi governador do Estado por pouco tempo, em Bagé, quando decidiu resistir ao golpe de Júlio de Castilhos. Com a Revolução Federalista (1893-1895), mesmo com idade avançada, foi nomeado General Comandante em Chefe do Exército Libertador. Foi o principal responsável pelas tratativas de pacificação em 1895, seguiu atuando na política estadual, vindo a falecer em 1906, em Bagé.

\footnotetext{
6 ANDRADE, Gustavo Figueira. A Trajetória Política do General João Nunes da Silva Tavares (Joca Tavares): Família, Comunicação e Fronteira. Dissertação (Mestrado em História) - Universidade Federal de Santa Maria, Santa Maria, 2017.

${ }^{7}$ Jornal A Federação, Porto Alegre, 7 out. 1885, p.2; Jornal A Federação, Porto Alegre, 20 mar. 1886, p. 2 Nessas datas, o Barão do Itaqui, General João Nunes da Silva Tavares é nomeado Comandante da Fronteira e Guarnição de Bagé.

${ }^{8}$ Jornal A Federação. Porto Alegre, 16 nov. 1889, p.1 - é veiculada nessa data a nomeação de todos os chefes de fronteiras no Rio Grande do Sul.

${ }^{9}$ Jornal A Federação. Porto Alegre, 31 ago. 1885, p.2 - Data é veiculada a nomeação de João Nunes da Silva Tavares, então Barão do Itaqui, ao cargo de Vice-Presidente da Província do Rio Grande do Sul.
} 
A partir destes aspectos, é possível pensar que sua atuação política e militar esteve imbricada ao espaço fronteiriço platino, principalmente no que tange a formação de suas redes de relações de poder, assim como para compreender sua liderança e mediação durante a Revolução Federalista de 1893-1895. Esta ligação com a fronteira pode ser evidenciada através de dois elementos.

O primeiro diz respeito à sua atividade econômica de estancieiro, pelos latifúndios que sua família possuía não apenas no Brasil como também no Uruguai, ligados à atividade pecuária e charqueadora, a qual permitiu a construção de redes de relações por compadrio e matrimônios, inclusive endogâmicos, enquanto estratégias sociais que estabeleceram vínculos com a família de Silveira Martins. Um segundo diz respeito a sua atuação individual enquanto militar ao longo do século XIX e início do XX, principalmente por participar de diversas campanhas militares, criou uma rede de relações de poder a partir de sua atuação militar, a qual envolvia desde os Presidentes de República brasileira, Marechais Deodoro da Fonseca e Floriano Peixoto, assim como no âmbito estadual (RS), com José Antônio Correa da Câmara, Visconde de Pelotas. Estas relações permitiram que ele, durante a Revolução Federalista em 1893, atuasse enquanto um mediador entre as lideranças federalista locais, as lideranças políticas e militares nacionais e as lideranças caudilhistas dentro do Partido Federalista.

Através de uma correspondência enviada pelo Almirante Luís Felipe Saldanha da Gama em 28 de março de 1895 ao General Tavares, além de destacar o perfil fronteiriço deste personagem, é possível evidenciar o quanto estas redes de relações federalistas, entendidas enquanto transnacionais, abrangiam o interior do Uruguai e como Joca Tavares enquanto um caudilho articulava e mediava o apoio destas redes transfronteiriças para o Exército Libertador, ao afirmar “[...] Já apelei para os amigos de Montevidéu. Queira Vossa Excelência fazer o mesmo para os de Cerro Largo e Taquarembó. Com o prestimoso auxílio de amigos como Galvão Machado, Baltazar Dias, Cândido Bastos [...] muitos outros se poderá conseguir [...]" (Assinado) Luís Felipe de Saldanha da Gama. (TAVARES, 2004, p. 224-227).

Essa influência e prestígio, associada ao conhecimento da fronteira e de suas peculiaridades que ao longo de sua vida pode desenvolver, construindo um espaço de experiência (KOSELLECK, 2006), que permitiram juntamente com Silveira Martins e outros líderes federalistas, organizar uma guerra civil que soube utilizar, estrategicamente, deste 
espaço fronteiriço, fato que também pôde ser observado durante a Revolução Farroupilha $(1835-1845)^{10}$.

A partir da relação do espaço fronteiriço com a formação das relações de poder construídas por estes indivíduos, iremos expor a especificidade destas relações de Joca Tavares e Silveira Martins, as quais permitem compreende-las como caudilhistas.

\section{ENTRE MILITARES E DOUTORES: A ATUAÇÃO DE SILVEIRA MARTINS E JOCA TAVARES ENQUANTO CAUDILHOS}

As revisões teóricas da História Política dos anos 1980 repensaram o político como um campo de estudo que abarca todos os atores sociais e suas relações de poder, buscando sua atuação no tempo curto dos eventos, relacionando tanto a abordagem micro quanto a macro (FÉRTIG, 2009). Tais reflexões permitem desvendar a trama das relações de poder social e familiar, o estabelecimento de redes (LANDÉ, 1977), as negociações, os sujeitos envolvidos, as trocas clientelísticas e as estratégias sociais dos indivíduos. Por meio das atuações políticas de Silveira Martins e Joca Tavares, identificamos diversas práticas como sendo características de uma atuação enquanto caudilhos.

Diferente de uma visão que por muito tempo se teve acerca dos caudilhos, imbuída de uma caráter pejorativo durante grande parte do século XIX e XX, influenciada pela visão desenvolvida pela "Geração de 1837" na Argentina (SHUMWAY 1993, p.131), ao longo do século XX, a atuação dos caudilhos foi repensada ao longo do século XX, passando a entender o caudilhismo enquanto um fenômeno social. Para Noemi Goldman e Ricardo Salvatore (1998), o caudilhismo passa a considerado enquanto parte de "um processo de construção do poder social e político, em conjunturas históricas particulares" (GOLDMAN; SALVATORE, 1998, p. 20).

Com o processo de formação do Estado Nacional das Províncias Unidas do Rio da Prata, futuramente Argentina (OZLAK, 1982), marcando um processo de transição para o Estado Moderno, o surgimento dos caudilhos segundo Valentina Ayrolo (2014), está relacionado à queda do sistema colonial, o qual possibilitou o desenvolvimento das autonomias locais. Neste sentido, os caudilhos podem ser definidos como especialistas no estabelecimento e manutenção de redes sociais, chefes militares cujo poder pode ser entendido como uma forma de

\footnotetext{
${ }^{10}$ Sobre a Revolução Farroupilha ver: GUAZZELLI, C. O horizonte da Província: a República Rio-grandense e os caudilhos do Prata (1835-1845). Porto Alegre: Linus, 2013.
} 
“dominação social” caracterizada pelo grande carisma pessoal, com apoio popular e ligados por fortes laços de lealdade com seus subordinados, sendo conhecidos pela sua capacidade de reunir homens em torno de seus objetivos, atuando também em torno de objetivos políticos (AYROLO 2014, p. 1). Agindo como mediadores entre os interesses locais e os nacionais/regionais conciliando com os seus e de seu segmento social, exerciam poder em sua localidade, ditando as regras do jogo do poder (GONZALBO, 1989), portanto, podiam ser entendidos como importantes elementos para a "consolidação de Estado Nacional" (AYROLO 2014, p. 3).

Os caudilhos, segundo Valentina Ayrolo "não desejavam anarquia, pelo contrário, desejavam manter a ordem social” (2014, p.3), eram pessoas influentes em suas localidades que, "utilizando suas redes de relações pessoais, trataram de erguer um sistema de alianças como base de uma ordem política estável" (HALPERIN apud GOLDMAN 1993, p.33). Sua atuação envolvia um sistema baseado na lealdade pessoal, além de diversas formas de dependência entre patrão e clientes, numa troca mútua, tanto com setores subalternos quanto com indivíduos economicamente superiores a eles, transformando-os em clientes e direcionando-os em prol de seus objetivos (SAFFORD, 1991, p. 63), de modo que, segundo Azua, sem o exercício distributivo, “o prestígio dos caudilhos não alcançaria grandes proporções" (1969, p. 124).

No Brasil, segundo Ieda Gutfreind (1998), até a década de 1970 a existência de uma corrente historiográfica rio-grandense de matriz Lusitana, que entendia a fronteira como uma linha de separação entre o luso e o hispânico, a qual era entendida como um espaço de conflitos e não de trocas, onde o território do Rio Grande do Sul já estava destinado a pertencer ao Brasil. A essa visão, contrapunha-se uma explicação de uma "matriz platina", contrária à visão de uma fronteira que separava a população que habitava os dois lados da fronteira, defendia a existência de importantes ligações entre as sociedades do Rio Grande do Sul e do Prata.

Essas perspectivas, ainda que com suas divergências, estimularam a ampliação e desenvolvimento das discussões e novas elaborações sobre os conceitos de fronteira. Atualmente, de acordo com Mariana Thompson Flores, as fronteiras são entendidas enquanto portadoras de "profundas ligações sociais, econômicas, militares, culturais e políticas entre as sociedades que habitaram esse espaço, forjadas desde os tempos coloniais" (2009, p.151). Diante desses elementos, partimos do entendimento de que o estado do Rio Grande do Sul fazia parte de uma região que ultrapassava os limites políticos nacionais (ARRIOLA, 2008), permitindo, portanto, compreender o caudilhismo enquanto uma prática social que também esteve presente no Brasil. 
O conceito de caudilhismo, segundo Élio Chaves Flores (1997), era entendido como uma relação de poder entre indivíduos e como um "conjunto de atividades, ações, ideias e projetos de chefes políticos denominados caudilhos" (FLORES 1997, p. 8). De acordo com o autor, o caudilho pode ser tanto um estancieiro ou militar experienciado em guerras, e que localmente atua enquanto liderança política, como o caso do General João Nunes da Silva Tavares. Por outro lado, o caudilho pode ser também um doutor, um indivíduo que além da fortuna pessoal, devido a seu grau de instrução, seu poder de oratória e persuasão, vem a ser um líder político regional ou mesmo nacional como Gaspar Silveira Martins.

O processo que envolveu a formação e ocupação do território que veio a ser o Rio Grande do Sul, durante o período Colonial, segundo Fernando Uricochea (1978), além de marcar a ampliação das fronteiras portuguesas, envolveu o surgimento de sujeitos que deveriam estar constantemente prontos para defender e manter essas conquistas, ocupando em seus territórios de atuação, o hiato deixado pelo poder central, os que podem ser entendidos como caudilhos.

Este período, entendido por Loiva Otero Félix (1996) como pastoril-militar, teria sido a origem do caudilhismo no Rio Grande do Sul, o qual veio a sofrer algumas modificações durante o Império. Para esta autora, a formação do Coronel no Império, esteve ligada a organização das famílias neste espaço, onde em geral, o chefe das mesmas era o chefe do bando de guerrilheiros que havia adquirido propriedade rural e se estabelecido na região fronteiriça. Neste sentido, o chefe que era o caudilho, "tão logo acabara o feito no qual se envolvia, dissolvia o bando, mas mantinha a liderança, na qualidade de estancieiro prestigiado, cercado por seus dependentes: peões, agregados, protegidos e escravos" (FÉLIX 1996, p. 38).

A cooptação dos caudilhos pelo poder central ocorria através de uma relação de trocas e lealdades, onde o enfraquecido governo imperial, necessitando negociar com as lideranças locais (FÉLIX, p. 1996), constituiu um Pacto Imperial que só vem a ser rompido com a Proclamação da República e a atuação do Partido Republicano Rio-Grandense, do qual fez parte o líder Júlio de Castilhos e Borges de Medeiros. Este pacto envolvia privilégios concedidos pelo governo central aos poderes locais, desde favorecimento em tarifas alfandegárias, vistas grossas ao contrabando e cumplicidades com desmandos nas práticas locais de poder. Em troca, essas lideranças locais recebiam a incumbência de representar o poder central, serem leais ao Imperador, garantindo a ordem social e política e as fronteiras do Império (FÉLIX 1996, p. 67$68)$. 
A relação entre os caudilhos militares e os caudilhos doutores era de constantes trocas, principalmente devido ao papel de mediador exercido por ambos, para que mantivessem seu prestigio e poder, sendo uma "dependência mútua" (SAFFORD 1991, p. 66). Suas redes de relações eram fator fundamental que estes mobilizavam para reunir colaboradores em torno de seus planos, como foi o caso de Silveira Martins que, após ter se destacado em nível nacional por ter ocupado diversos cargos políticos de confiança do Imperador além de ter sido membro vitalício do Conselho de Estado e importante líder do Partido Liberal durante o Império no Brasil, contava com uma rede maior de relações não apenas no país como também no Uruguai e na Argentina, de onde comandou politicamente a Revolução Federalista de 1893-1895, articulando colaboradores e organizando apoios e suprimentos.

As relações clientelistas construídas através dos vínculos fronteiriços destes personagens, que incluíam suas origens familiares transnacionais e sua inserção nos mais altos cargos do Império, ajudam a entender a participação histórica destes núcleos familiares nos conflitos da Guerra Cisplatina, da Revolução Farroupilha (1835-1845) e na Revolução Federalista (1893-1895). Ou seja, percebe-se a herança liberal farroupilha de Gaspar Silveira Martins, oriundo desse envolvimento familiar, nos conflitos platinos ${ }^{11}$.

\section{A ATUAÇÃO DE GASPAR SILVEIRA MARTINS E JOÃO NUNES DA SILVA TAVARES NA REVOLUÇÃO FEDERALISTA}

Com o fim do Império, o processo de institucionalização do republicanismo no Brasil foi sendo construído a partir da destituição do poder de grande parcela dos liberais e também conservadores que exerciam cargos políticos, públicos e militares em suas províncias, os quais haviam permanecido no poder mediante uma relação de troca de favores e alianças políticas construídas entre elites regionais/provinciais e o Império.

No Rio Grande do Sul, com a emergência do Partido Republicano Rio-grandense (PRR), a construção do governo republicano provocou alguns embates entre as elites, especialmente uma parcela da elite oriunda do Partido Liberal, Partido Conservador e dissidentes republicanos

\footnotetext{
${ }^{11}$ Para mais informações sobre os pedidos e trocas de favores solicitados a Gaspar Silveira Martins, quando este ocupava os cargos de Ministro, Deputado e Senador, e sobre o envolvimento de sua família nos conflitos platinos, ver a dissertação de mestrado: ROSSATO, Monica. Relações de poder na região fronteiriça platina: família, trajetória e atuação política de Gaspar Silveira Martins. 163f. Dissertação (Mestrado em História). Programa de Pós-Graduação em História, UFSM, Santa Maria, 2014.
} 
que se organizaram sob o título de Partido Federalista (1892), ao se contraporem ao modelo de organização do governo estadual, federalista, de inspiração positivista de Júlio de Castilhos.

Nesse sentido, o Partido Federalista foi organizado em 1892, no momento em que o principal líder do antigo Partido Liberal retornou de seu exílio na Europa. Gaspar Silveira Martins havia sido exilado pelo governo provisório de Deodoro da Fonseca, logo após a Proclamação da República retornando ao país no início de 1892. Com a criação do Partido Federalista, as atuações de Silveira Martins e Joca Tavares (ex-integrante do Partido Conservador) se unem em torno da causa federalista. Os federalistas reclamavam principalmente do autoritarismo, centralização do poder, da Constituição de 14 de Julho, posto em prática por Júlio de Castilhos, com inspiração positivista, e da interferência do poder central (federal) de Floriano Peixoto a favor deste governo castilhista no Rio Grande do Sul.

Como Silveira Martins, Joca Tavares e suas famílias possuíam terras no Uruguai, percebe-se a constante movimentação deles e de outros líderes por essa região, para a organização das invasões em direção ao território do Rio Grande do Sul. Nesse momento, a casa de Silveira Martins no Uruguai, transformou-se no quartel-general dos revolucionários, onde eram realizadas reuniões para a obtenção do armamento e de contribuições de fazendeiros da região (SOUZA, 2008). Na Argentina e no Uruguai, Silveira Martins atuou na mobilização de suas redes de poder, no que muito contribuiu sua experiência fronteiriça e transnacional de contatos construída ainda durante o Império, pois sua movimentação para a aquisição de recursos implicava mobilizar esses contatos, amigos e correligionários a contribuir para os federalistas.

Isso fica perceptível em uma correspondência que Silveira Martins envia a Eduardo Prado, comunicando-o de que ele assumiria o cargo de agente confidencial da Federalista na Europa $^{12}$. Em Buenos Aires, Silveira Martins esteve em contato com o político Leandro Além, chefe da União Cívica Radical, que pretendia obter a ajuda de Silveira Martins para o conflito na Argentina e, em troca, oferecia apoio em forma do fornecimento de armamento e munição para os federalistas (MARTINS, 1929).

No Uruguai, a imprensa periódica publicava notícias relacionadas a Revolução Federalista, incluindo a publicação de conferências realizadas por Silveira Martins. O jornal "El eco nacionalista", publicado em Melo no Uruguai, reproduziu uma entrevista em que Silveira Martins demonstrou o seu descontentamento em relação ao governo republicano e a

\footnotetext{
${ }^{12}$ MARTINS, Gaspar Silveira. Carta a Eduardo Prado. Buenos Aires. Coleção Revolução Federalista de 1893. Biblioteca Nacional do Rio de Janeiro, RJ, Brasil.
} 
intervenção de Floriano Peixoto no Rio Grande do Sul, em auxílio a Julio de Castilhos ${ }^{13}$. Demonstrava também indícios do apoio que os federalistas recebiam do governo uruguaio, o qual preocupava-se sobre o que ocorria no Rio Grande do $\mathrm{Sul}^{14}$.

Além do Uruguai, onde muitos estancieiros brasileiros e sua própria família possuíam propriedades, Silveira Martins circulou pela Argentina em busca de recursos e apoio ao conflito, especialmente em Bueno Aires e nas províncias litorâneas de Corrientes e Entre Ríos. Circulação que fica evidente nas correspondências trocadas entre os principais chefes envolvidos no conflito como o General Joca Tavares, Francisco da Silva Tavares, Almirante Saldanha da Gama, Gumercindo Saraiva, Aparício Saraiva, Joaquim Pedro Salgado, entre outros $^{15}$ e nas correspondências das legações brasileiras em Buenos Aires, que apontavam uma desconfiança das autoridades brasileiras em relação ao governo argentino, por suas relações diretas e indiretas com Gaspar Silveira Martins e pela possibilidade de entrada de armamentos e munições aos federalistas por vias argentinas ${ }^{16}$.

Nas correspondências, fica clara a atuação de Silveira Martins na aquisição de armamentos, cavalos, recursos e demais materiais necessários a manutenção das tropas na guerra, como erva-mate, roupas, e comida, contando para isso com o auxílio de empréstimos já que "esgotados os recursos pecuniários [fl.22v.] tratava de obter um empréstimo em Buenos Aires"17. Os mais íntimos chamavam a residência de Silveira Martins de "Itamaraty", pela articulação e mobilização de recursos e pessoas para o conflito que se davam naquele espaço ${ }^{18}$.

\footnotetext{
${ }^{13}$ UNA CONFERENCIA com Gaspar Silveira Martins. El Eco Nacionalista, 20 mar. 1893, p. 2 e 3. Periódico encontrado na Biblioteca Nacional do Uruguai, Montevidéu, Uruguai.

${ }^{14}$ RIO GRANDE. La revolución em pie. Opiniones de Silveira Martins. Um reportaje. (De La Tarde). El Eco Nacionalista, 08 abr. 1893, p. 2 e 3. Periódico encontrado na Biblioteca Nacional do Uruguai, Montevidéu, Uruguai.

${ }^{15}$ Correspondências publicadas nas obras: TAVARES, Francisco da Silva. Diário da Revolução Federalista de 1893. Organização: Corálio Bragança Pardo Cabeda, Gunter Axt e Ricardo Vaz Seeling. Porto Alegre: Procuradoria Geral - Geral de Justiça, Projeto Memória. Tomo I, 2004; TAVARES, João Nunes da Silva. Diário da Revolução Federalista de 1893. Organização: Corálio Bragança Pardo Cabeda, Gunter Axt e Ricardo Vaz Seeling. Porto Alegre: Procuradoria Geral - Geral de Justiça, Projeto Memória. Tomo II, 2004; GAMA, Luiz Felipe de Saldanha da. Diário e Correspondências do Almirante Saldanha da Gama. Porto Alegre: Sulina, 2009.

${ }^{16}$ MINISTÉRIO DAS RELAÇÕES EXTERIORES. Reservados e Confidenciais. Rio de Janeiro, 6 abr. 1893. Arquivo Histórico do Itamaraty, Rio de Janeiro.

${ }^{17}$ Correspondência de Gaspar Silveira Martins a Francisco da Silva Tavares, 20 abr. 1893. In: TAVARES, Francisco da Silva. Diário da Revolução Federalista de 1893. Organização: Corálio Bragança Pardo Cabeda, Gunter Axt e Ricardo Vaz Seeling. Porto Alegre: Procuradoria Geral - Geral de Justiça, Projeto Memória. Tomo I, 2004, p. 109.

${ }^{18}$ TAVARES, Francisco da Silva. Correspondência, 13 ago. 1893. In: TAVARES, Francisco da Silva. Diário da Revolução Federalista de 1893. Organização: Corálio Bragança Pardo Cabeda, Gunter Axt e Ricardo Vaz Seeling. Porto Alegre: Procuradoria Geral - Geral de Justiça, Projeto Memória. Tomo I, 2004, p. 132.
} 
Sua rede de relacionamentos mobilizada em momentos de conflito contava ainda com pessoas localizadas na Europa, que trabalhavam a favor da causa federalista, na busca de empréstimos e apoio a guerra civil. Vínculos construídos anteriormente, durante o Império, e reafirmados em suas viagens a Europa, durante seu exílio (fim de 1889 a 1891) e viagem posterior realizada entre 1894 e 1895. Foi o caso de Eduardo Prado, informante dos federalistas através da imprensa e da tentativa de busca de recursos para a Revolução na Europa, e de Jose Carlos Rodrigues, jornalista e correspondente do "Jornal do Commercio" na Europa ${ }^{19}$.

Nesse sentido, evidenciam-se as complexas redes fronteiriças transnacionais que iam além da contribuição de proprietários e estancieiros da região fronteiriça, chegando até mesmo na Europa, na articulação de Silveira Martins nesse espaço fronteiriço platino e fora dele, especialmente no contexto de consolidação da República. A fronteira apresentou-se como um espaço de fuga, encontro, de articulação, apoio e defesa dos projetos políticos de Silveira Martins, em um processo de territorialização de poder construído ao longo de sua trajetória política e mobilizado no contexto convulsionado pelos conflitos entre federalistas e republicanos nos primeiros anos da República.

No caso do General Joca Tavares, durante a República, sua atuação na Guarda Nacional e no comando Militar da Fronteira, representavam, além dos aspectos militares, elementos de atuação política e cooptação das elites caudilhescas locais, pois ao mesmo tempo em que mediavam favores com o governo central, permitiam o estabelecimento de relações clientelistas (FÉRTIG, 2010). Por outro lado, esses elementos permitiriam mobilizar as forças sob seu comando em prol de seus interesses políticos ou militares ou auxiliar os caudilhos doutores.

Durante a Revolução Federalista de 1893, Silveira Martins e Joca Tavares, articularam todo seu poder e prestígio construído durante o Império na mobilização de recursos humanos e materiais para organizar o Exército Libertador ${ }^{20}$. Além de ambos possuírem estâncias em Bagé e em Cerro Largo, no Uruguai, eram amigos pessoais. Em carta enviada por Silveira Martins de Montevidéu ao General Joca Tavares, a relação de proximidade entre os dois líderes fica evidente, "Meu caro general, recebi sua carta; agradeço-lhe o acolhimento que fez a meu filho J. Julio; ele é um tanto indócil, mas é um bravo soldado como terá ocasião de certificar-se (...). Montevidéu, 16 de setembro de 1893" (TAVARES, 1893).

\footnotetext{
${ }^{19}$ MARTINS, Gaspar Silveira. Carta a José Carlos Rodrigues. Londres, 19 abr. 1890. Manuscritos. Coleção José Carlos Rodrigues. Biblioteca Nacional do Rio de Janeiro, RJ, Brasil.

${ }^{20}$ Nome pela qual era conhecida a força militar federalista.
} 
A influência, prestígio e o poder dos caudilhos, segundo Valentina Ayrolo (2014) exímios mediadores, eram exercidos de diversas formas, negociando favores e lealdades. Dentro da estrutura de comando do Exército Libertador, o General Tavares desempenhava a função de mediador entre caudilhos menores, chefes de suas localidades, com quem negociava constantemente, e a liderança política de Silveira Martins, o chefe político. Em carta enviada pelo General Tavares ao Coronel Mateus Collares, em 17 de janeiro de 1895, negocia com esta liderança militar federalista, pois ao mesmo tempo em que promete que após o término da contenda os interesses pessoais serão atendidos, pede obediência às suas ordens, afirmando que “(...) Precisamos união e pôr termo a essas intermináveis divergências entre chefes tão bravos e tão dignos como sois. Depois da causa defendida, liquidar-se-ão as contas, eu passarei tudo a limpo e cada macaco ficará em seu galhinho" (TAVARES, 2004 p. 180).

Através de uma carta enviada ao General Tavares por Cônego João Inácio Bittencourt e Pedro Rodrigues de Borba, em 1 de novembro de 1893, ele caracteriza as redes de relações caudilhescas, "Exmo. Sr. General Tavares [...] Saudamos a Vossa Excelência e sentimos grande prazer em estarmos debaixo da vossa proteção. De Vossa Excelência etc, etc. João Inácio de Bittencourt e Pedro R. de Borba" (TAVARES, 2004, p. 65. Grifo do autor).

Por meio desta carta, exemplificamos o prestígio enquanto caudilho e a proteção que dispensava aos seus protegidos, a qual poderia ser a concessão de um favor ou benefício, uma proteção contra as investidas dos inimigos. Estes protegidos poderiam familiares, amigos, políticos em geral, os quais geralmente colocam-se sob a proteção de Joca Tavares expressando também a manifestação de lealdade de seus protegidos. O clientelismo neste período de conflito pode ser entendido enquanto uma política de trocas de favores, para com seus subordinados, seus amigos ou correligionários políticos. No que tange a essa prática clientelística, Ana Frega, em Los Orientales em armas: estúdios sobre la experiência militar em la revolución artiguista (2015), ao falar sobre as experiências militares e as identidades sociais e políticas, permite o entendimento de que, por não se tratar de uma relação que envolve o Estado, o desafio de manter seus soldados engajados e a adesão dos colaboradores da Revolução, envolvia uma relação contratual (FREGA, 2015, p. 26), tornando necessário, portanto, que fossem atendidos os interesses dos diversos envolvidos no conflito para que sua liderança fosse efetiva.

Dentre as correspondências pessoais do General Tavares, os telégrafos também evidenciam essa atuação caudilhesca e a rede de relações deste com lideranças políticas de diversas localidades do Rio Grande do Sul, tais como Santana do Livramento, Canguçu, Piratini, Caçapava do Sul, Dom Pedrito, Bagé, São Gabriel, São Borja, Rosário do Sul, Pelotas, 
Cacimbinhas (Pinheiro Machado), Pedras Altas, Herval, Arroio Grande, Jaguarão, Porto Alegre e outras localidades no Uruguai e Argentina.

Neste sentido, através destas mensagens telegráficas são evidenciados diversos aspectos de sua atuação enquanto caudilho, os quais apresentaremos a seguir. Em telégrafo enviado da cidade de Santa do Livramento, por um correligionário político de nome Hipólito Cabeda, em 15 de janeiro de 1892, este solicita a mediação de Joca Tavares, dizendo: "Peço-vos minha nomeação Juiz Municipal ai” (Acervo Particular da senhora Yara Maria Botelho Vieira, Bagé, RS. Transcrição de Gustavo F. Andrade, 2016).

Em outro telégrafo enviado em 3 de fevereiro de 1892, a mediação de Joca Tavares é solicitada por lideranças locais. Em meio ao conturbado contexto político e social no Rio Grande do Sul, conhecido por "Governicho"21, o Chefe de Polícia de São Gabriel, José Serafim Castilhos (Juca Tigre), importante liderança política e caudilhesca daquela cidade, pede que este telegrafe ao Visconde de Pelotas solicitando que "[...] mande destacar 50 praças um oficial confiança quinto Regimento, força aqui reduzida" (Acervo Particular da senhora Yara Maria Botelho Vieira, Bagé, RS. Transcrição de Gustavo F. Andrade, 2016).

Muitos dos caudilhos das diversas localidades locais enviavam telégrafos falando dos aprestamentos militares e colocando suas forças a disposição do General Tavares, ou organizando-as segundo suas ordens.

Da cidade de Caçapava, Laurentino Filho, chefe das forças nomeadas "populares", naquela localidade, envia diversos telégrafos ao General Tavares. Em telégrafo enviado em 11 de fevereiro de 1892, assevera a Joca que "aqui estamos agindo, reuniões revolucionárias, pouca força temos aqui onde oposição é forte, pedimos urgência força aqui, que venha armada, já dei todo andamento tendo mandar forças diversos pontos mande urgência” (Acervo Particular da senhora Yara Maria Botelho Vieira - Bagé. Transcrição de Gustavo F. Andrade, 2016).

Estas correspondências, além de evidenciar a amplitude das redes de relações tanto de Joca Tavares quanto de Silveira Martins, demonstram a amplitude dos assuntos que poderiam ser tratados, desde a capacidade de arregimentar forças políticas e militares, relações clientelísticas e o prestígio pessoal que desfrutavam. É por meio desta relação de confiança entre remetente e destinatário que evidencia-se o poder destes caudilhos enquanto mediadores e sua influência num espaço fronteiriço no qual atuavam e territorializavam para comandar

\footnotetext{
${ }^{21}$ De acordo com Franco (2012), em novembro de 1891 o governador do Rio Grande do Sul, Júlio de Castilhos, foi deposto após apoiar o golpe efetuado pelo Presidente da República, Manoel Deodoro da Fonseca, situação que terminou com a deposição de ambos. Nesse período, no Rio Grande do Sul, ocorreu uma sucessão de governos malsucedidos gerando um sentimento de anarquia, alcunhado por Júlio de Castilhos como "Governicho".
} 
política e militarmente as forças federalistas num contexto que confrontou seus interesses as relações de poder em que estes exerciam certa primazia.

Dessa forma, assim como no Uruguai e na Argentina, a segunda metade do século XIX marcou o fortalecimemnto do estado nacional e, principalmente a partir de 1880, o período em que o caudilhismo se enfraqueceu. No sul do Brasil, especialmente no estado do Rio Grande do Sul, a Revolução Federalista de 1893 foi uma guerra civil que rompeu com o Pacto Imperial (FÉLIX, 1996, p. 67-68), contrapondo caudilhos dos dois lados do conflito, inseridos no conturbado contexto de transição da monarquia para a República, marcado por transformações sociais e políticas, onde o poder dos caudilhos foi sendo controlado e cooptado por meio de negociaçõespelas estruturas republicanas, fortalecidas burocratica e militarmente, a partir das quais, tornou-se possível a supremacia de sua autoridade e a realização de projetos políticos, nos quais também estavam contemplados os interesses das lideranças locais que os apoiavam.

\section{CONSIDERAÇÕES FINAIS}

Neste texto, elencamos a base fronteiriça nas trajetórias de Gaspar Silveira Martins e João Nunes da Silva Tavares em suas redes de poder familiares, clientelísticas caudilhescas e políticas. O envolvimento destes personagens na Revolução Federalista traz para o centro da análise as especificidades das experiências construídas por eles no âmbito local/fronteiriço e como esta região fronteiriça patina constrói uma elite política que a mobiliza na implementação de seus projetos.

Uma elite articulada transnacionalmente, por seus vínculos e relações de poder, que incluíam ideias e projetos políticos a serem pensados e propostos para a organização do Estado Nacional brasileiro. Foi o que observamos na trajetória de Silveira Martins e em Joca Tavares, a organização e a mobilização de uma base de alianças e de suas redes que compartilhavam e aderiram à causa federalista.

Assim, ao acompanharmos o percurso individual de cada personagem evidenciamos outras possibilidades de compreensão do passado e as especificidades de suas experiências e relações de poder internacionais, e que busca não restringir-se a uma história de análise de discursos e linguagens das ideias de um partido. Nesse intuito, as pesquisas sobre Silveira Martins e Joca Tavares auxiliam na observação do processo histórico da sociedade fronteiriça e que, por suas trajetórias de experiências, caminhos e interrelação com outros sujeitos, bem como as escolhas tomadas trazem outros significados para as compreensões de fronteira, de 
política e de sociedade do século XIX e contribuem para o aprofundamento da temática no âmbito da história política.

\section{REFERÊNCIAS BIBLIOGRÁFICAS}

ANDRADE, Gustavo Figueira. A trajetória política do General João Nunes da Silva Tavares (Joca Tavares): família, comunicação e fronteira. Dissertação (Mestrado História). Santa Maria: Programa de Pós-Graduação em História, UFSM, 2017.

ARRIOLA, Arturo Taracena:Propuesta de definición histórica para región. Estúdios de Historia Moderna y Contemporânea de México, n. 35, Janeiro-Junho, 2008, p. 181-204.

AYROLO, Valentina; MÍGUEZ, Eduardo J. Reconstruction of the Socio-Political Order after Independence in Latin America. A Reconsideration of Caudillo Politics in the River Plate". Jahrbuchfür Geschichte Lateinamerikas, n.49, 2012.

AZUA, Carlos Real de. Legitimidad, apoyo y poder político: ensaio de tipologia. $1^{\text {a }}$ Ed. Montevideo: Fundación de Cultura Universitaria, 1969.

BISCHOFF, Alvaro W. João Nunes da Silva Tavares. In: TAVARES, João Nunes da Silva. Diário da Revolução Federalista de 1893. Organização: Corálio Bragança Pardo Cabeda, GunterAxt e Ricardo Vaz Seeling. Porto Alegre: Procuradoria Geral - Geral de Justiça, Projeto Memória, 2004, Tomo II. (Memória Política e Jurídica do Rio Grande do Sul, 3).

BOISSEVAN, Jeremy. "Manipolatorisociali: mediatori come imprenditori” AA. VV RETI. L'analisi di networknellescienzesociali. Roma: Donzelli ed., 1995.

CARVALHO, José Mario. Nobiliário sul-riograndense: $2^{\mathrm{a}}$ Ed. Porto Alegre: EDIGAL, 2011.

GONZALBO, Femando Escalante. Ciudadanos imaginarios. Memorial de los afanes y desventuras de lavirtud y apologíadel vicio triunfante em la república mexicana. Tratado de moral pública, México, Colegio de México, 1993. 
FARINATTI, Luís Augusto E.; THOMPSON FLORES, Mariana F. da C. A fronteira manejada: apontamentos para uma história social da fronteira meridional do Brasil (século XIX). In: HEINZ, Flávio (org.). Experiências nacionais, temas transversais: subsídios para uma história comparada da América Latina. São Leopoldo: Oikos, 2009.

FÉLIX, Loiva Otero. Coronelismo, borgismo e cooptação política. 2. Ed. Porto Alegre: Editora UFRGS, 1996.

FÉRTIG, André A. A História política: da história tradicional à história renovada. Territórios e Fronteiras, Cuiabá, PPG em História/UFMT, v.2, n.2, jul./dez., 2009.

Clientelismo político em tempos belicosos: a Guarda Nacional da Província no Rio Grande do Sul na defesa do Império do Brasil (1850-1873). Santa Maria: Editora da UFSM, 2010.

FLORES, Élio Chaves. O caudilhismo. São Paulo: FTD, 1997.

FRANCO, Sergio da Costa. Júlio de Castilhos e sua época. Porto Alegre: Ed. Universidade/UFRGS, 1988.

FRANCO, S. da C. A Guerra Civil de 1893. 2. ed. ampl. Porto Alegre: Edigal, 2012.

GOLDMAN, N.; SALVATORE, R. (Orgs.) Caudillismos Rioplatenses: nuevas miradas a un viejo problema. Buenos Aires: Eudeba, 1998.

GUAZZELLI, C. O horizonte da Província: a República Rio-grandense e os caudilhos do Prata (1835-1845). Porto Alegre: Linus, 2013.

GUTFREIND, Ieda. Rio Grande do Sul: 1889-1896. A Proclamação da República e a Reação Liberal através de sua Imprensa. (Dissertação de Mestrado) Porto Alegre, PUC, 1979. 
. A Historiografia Rio-grandense. Porto Alegre: EDUFRGS, 1998.

KOSELLECK, Reinhart. Futuro Passado: contribuição à semântica dos tempos históricos. Rio de Janeiro: Contraponto: Ed. PUCRJ, 2006.

LANDÉ, Carl H. A base diádica do clientelismo. In: SCHIMIDT, S.W. et. al. (eds.). Friends, followers and factions. Berkeley: University of California Press, 1977, p 13-38.

MARTINS, Gaspar Silveira. Carta a Eduardo Prado. Buenos Aires. Coleção Revolução Federalista de 1893. Biblioteca Nacional do Rio de Janeiro, RJ, Brasil, 1894.

MARTINS, José Julio S. Silveira Martins. Rio de Janeiro: Typ. São Benedicto, 1929.

OZLAK, Oscar. La conquista delorden y lainstitucionalizacióndel Estado. In: La formacióndel Estado Argentino. Buenos Aires: Editora Belgrano, 1982, p. 95-190.

PADOIN, M. Medianeira. O federalismo na propaganda republicana no Rio Grande do Sul: uma retrospectiva histórica. In: AXT, Gunter [et al.] (Org.). Julio de Castilhos e o paradoxo republicano. Porto Alegre: Nova Prova, 2005.

PADOIN, M. Medianeira; ROSSATO, Monica. Gaspar Silveira Martins: Perfil biográfico, discursos e atuação na Assembleia Provincial. Porto Alegre: Assembleia Legislativa do Estado do Rio Grande do Sul, 2013.

PESAVENTO, Sandra J. História do Rio Grande do Sul. Porto Alegre: Mercado Aberto, 1984.

PICCOLO, Helga Iracema. L. A política rio-grandense no Segundo Império (1868-1882). Porto Alegre: IFCH/UFRGS, 1974.

. Vida Política no século XIX: da descolonização ao movimento Republicano. Porto Alegre: Ed. UFRGS, 1992.

REIS, Jorge. Apontamentos Históricos e Estatísticos de Bagé. Bagé: Tipografia do Jornal Correio do Povo, 1911. 
ROSSATO, Monica. Relações de poder na região fronteiriça platina: família, trajetória e atuação política de Gaspar Silveira Martins. 163f. Dissertação (Mestrado em História). Programa de Pós-Graduação em História, UFSM, Santa Maria, 2014.

SAFFORD, Frank. Politica, Ideologia y Sociedad.In: In: BETHEL, Leslie (coord). Historia de America Latina: América latina independiente, 1820-1870. BETHEL, Leslie (coord) v.6, p. 42-104, 1991.

SHUMWAY, Nicolas. La Generación de 1837, Parte I. In: La invención de la Argentina. Historia de una idea. Buenos Aires: Emecé Editores, 1993, p.131- 163.

SOUZA, Suzana Bleil de. Fronteira Poder Político e articulações comerciais no Brasilmeridional do final do século XIX. Anuário IEHS, 2008, p. 305 - 333.

TAVARES, João Nunes da Silva. Diário da Revolução Federalista de 1893. Organização: Corálio Bragança Pardo Cabeda, GunterAxt e Ricardo Vaz Seeling. Porto Alegre: Procuradoria Geral - Geral de Justiça, Projeto Memória, 2004, Tomo II. (Memória Política e Jurídica do Rio Grande do Sul, 3).

TRINDADE, Helgio; NOLL, Maria I. Rio Grande da América do Sul: partidos e eleições(1823-1990). Porto Alegre: Ed. UFRGS/ Sulina, 1991.

URICOCHEA, Fernando. O minotauro imperial. São Paulo: DIFEL, 1978.

VARGAS, J. M. Pelas margens do Atlântico: um estudo sobre elites locais e regionais no Brasil a partir das famílias proprietárias de charqueadas em Pelotas, Rio Grande do Sul (século XIX). Tese (Doutorado em História)-Universidade Federal do Rio de Janeiro, Rio de Janeiro, 2013.

\section{REFERÊNCIAS DOCUMENTAIS}


CABEDA, H. [Telegrama] 15 jan. 1892, Santana do Livramento. [para] TAVARES, João Nunes da Silva. Bagé, 1 folha. Pedido de nomeação para juiz. Acervo Particular da senhora Yara Maria Botelho Vieira, Bagé, RS. Transcrição de Gustavo F. Andrade, 2016.

CASTILHOS, J. S. [Telegrama] 12 fev. 1892, São Gabriel. [para] TAVARES, João Nunes da Silva. Bagé, 1 folha. Perseguição à grupos sediciosos em São Gabriel. Acervo Particular da senhora Yara Maria Botelho Vieira, Bagé, RS. Transcrição de Gustavo F. Andrade, 2016.

FILHO, L. [Telegrama] 11 fev. 1892, Caçapava do Sul. [para] TAVARES, João Nunes da Silva. Bagé, 1 folha. Comunica forte oposição na cidade e pede envio de reforços armados com urgência. Acervo Particular da senhora Yara Maria Botelho Vieira, Bagé, RS.

Transcrição de Gustavo F. Andrade, 2016.

\section{REFERÊNCIAS HEMEROGRÁFICAS:}

A Federação. Porto Alegre, 7 out. 1885, p.2.

A Federação. Porto Alegre,20 mar. 1886, p.2

A Federação. Porto Alegre,16 nov. 1889, p.1.

A Federação. Porto Alegre, 31 ago. 1885, p.2.

EI Eco Nacionalista. 20 mar. 1893, p. 2 e 3. 